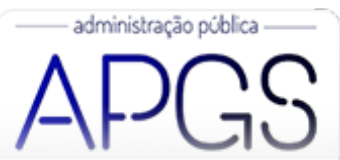

Administração Pública e Gestão Social ISSN: 2175-5787

apgs@ufv.br

Universidade Federal de Viçosa

Brasil

\title{
Vigiar ou Educar: A Governança Ambiental como Experiência
}

Matarazzo, Gustavo; Quintão, Felipe; Serva, Maurício

Vigiar ou Educar: A Governança Ambiental como Experiência

Administração Pública e Gestão Social, vol. 13, núm. 2, 2021

Universidade Federal de Viçosa, Brasil

Disponible en: http://www.redalyc.org/articulo.oa?id=351566014008

\section{(c) $(1) \Theta$}

Esta obra está bajo una Licencia Creative Commons Atribución-NoComercial-SinDerivar 3.0 Internacional. 


\section{Vigiar ou Educar: A Governança Ambiental como Experiência}

Discipline or Educate: Environmental Governance As Experience
Vigilar o educar: La Gobernanza Ambiental como Experiencia

Gustavo Matarazzo

Instituto Federal de Educação, Ciência e Tecnologia de São

Paulo - Câmpus Capivari, Brasil

gmatarazzo.rezende@gmail.com

Felipe Quintão

Instituto Federal de Santa Catarina: Florianópolis, SC, BR,

Brasil

frquintao@gmail.com

Mauricio Serva

Universidade Federal de Santa Catarina, Brasil

mauserva@gmail.com
Redalyc: http://www.redalyc.org/articulo.oa? $\mathrm{id}=351566014008$

Recepción: 08 Mayo 2020

Aprobación: 30 Octubre 2020

Publicación: 01 Abril 2021

\section{Resumo:}

Objetivo da pesquisa: compreender como se desenvolvem as experiências dos sujeitos em organizações que atuam em ações de governança ambiental.

Enquadramento teórico: argumentamos sobre a necessidade de problematizar as correntes teóricas fundadas na cisão entre cultura e natureza a fim de analisar organizações ligadas à governança ambiental. Para isso, partimos da noção de irredutibilidade da experiência, proposta por autores do pragmatismo filosófico e sociológico. A partir dela, apresentamos os conceitos de preensão, prova, investigação e materialidade, que serviram como operadores analíticos para a investigação das experiências das organizações pesquisadas.

Metodologia: analisamos os materiais de duas pesquisas de cunho etnográfico realizadas na cidade de Florianópolis, Santa Catarina. Nos dois casos, empregamos observação participante complementada com entrevistas semiestruturadas.

Resultados: observamos que os processos de governança estão fundamentados no conflito e são dependentes das negociações acerca das expectativas normativas a respeito das finalidades e objetivos organizacionais. Ressaltamos também que as ações desenvolvidas pelos sujeitos são permeadas por uma tensão entre as finalidades de educação ambiental e de vigilância.

Originalidade: governança ambiental é um conceito que, historicamente, tem sido adotado a partir de suas perspectivas macrossociológicas. Na presente pesquisa, apresentamos o fenômeno de governança ambiental por meio das experiências dos sujeitos, sustentados em uma epistemologia pragmatista.

Contribuiçóes teóricas e práticas: a pesquisa demonstra que o posicionamento epistemológico escolhido permite ampliar o debate acerca da governança ambiental, trazendo outras escalas de análises e evidenciando aspectos, frequentemente, obliterados do fenômeno. Em termos práticos, o estudo aponta para a tensão inerente entre as lógicas de ação relacionadas com as finalidades de educação ambiental e de vigilância.

PalaVRaS-CHAVE: Governança ambiental, organizações, conflito, vigilância, expertises.

\section{Abstract:}

Research objective: The objective of this research is to understand the development of individual experiences in organizations that act in the field of environmental governance.

Theoretical framework: we indicate the need to question the theoretical framework rooted on the division between culture and nature in order to analyze organizations related to environmental governance. To do so, we start from the notion of irreducibility of the experience, proposed by authors of philosophical and sociological pragmatism. From there, we present the concepts of 
prehension, proof, inquiry and materiality that were used as analytical operators for the investigation of the experiences of the organizations surveyed.

Methodology: we analyzed the data of two ethnographic studies carried out in the city of Florianópolis, in the state of Santa Catarina, Brazil. In both studies, we applied the methods of participant observation and semi-structured interviews.

Results: we observed that governance processes are based on conflicts and depend on negotiations regarding normative expectations carried by distinct actors regarding the purposes and goals of the organization. We also highlighted that the actions developed by individuals reflect a tension between two different purposes, the purpose of environmental education and the purpose of surveillance of the territory to be managed.

Originality: environmental governance is a concept that, historically, has been adopted from its macro-sociological perspectives. In the present research, we present the phenomenon of environmental governance through the experiences of the subjects, supported by a pragmatic epistemology.

Theoretical and practical contributions: the research demonstrates that the chosen epistemological positioning allows to broaden the debate about environmental governance, bringing other scales of analysis and highlighting aspects, often obliterated of the phenomenon. In practical terms, the study points to the inherent tension between the logic of action related to the purposes of environmental education and surveillance.

KEYWORDS: Environmental governance, organizations, conflict, surveillance, expertise.

\section{Resumen:}

Objetivo de la investigación: este artículo busca comprender cómo se desarrollan las experiencias de los individuos en organizaciones que operan en acciones de gobernanza ambiental.

Marco teórico: discutimos sobre la necesidad de problematizar las corrientes teóricas fundadas en la división entre cultura y naturaleza para analizar organizaciones vinculadas a la gobernanza ambiental. Para ello partimos de la noción de irreductibilidad de la experiencia, propuesta por autores del pragmatismo filosófico y sociológico. A partir de este punto, se presentan los conceptos de captación, prueba, investigación y materialidad que sirvieron como operadores analíticos para la investigación de las experiencias de las organizaciones investigadas.

Metodología: analizamos los materiales de dos estudios etnográficos realizados en la ciudad de Florianópolis, en el estado de Santa Catarina, Brasil. En ambos casos, utilizamos la observación participante complementada con entrevistas semiestructuradas.

Resultados: observamos que los procesos de gobernanza se basan en conflictos y dependen de negociaciones sobre expectativas normativas con respecto a propósitos y objetivos organizacionales. También enfatizamos que las acciones desarrolladas por los sujetos están impregnadas por una tensión entre los propósitos de la educación ambiental y la vigilancia.

Originalidad: la gobernanza ambiental es un concepto que, históricamente, ha sido adoptado desde sus perspectivas macrosociológicas. En la presente investigación, presentamos el fenómeno de la gobernanza ambiental a través de las experiencias de los sujetos, apoyados en una epistemología pragmática.

Contribuciones teóricas y prácticas: la investigación demuestra que el posicionamiento epistemológico elegido permite ampliar el debate sobre la gobernanza ambiental, aportando otras escalas de análisis y destacando aspectos, muchas veces obliterados del fenómeno. En términos prácticos, el estudio apunta a la tensión inherente entre la lógica de acción relacionada con los propósitos de la educación y vigilancia ambiental.

Palabras ClaVE: Gobernanza ambiental, organizaciones, conflictos, vigilancia, expertise.

\section{INTRODUÇÃO}

"Governança" é um termo que se origina no mundo empresarial (Lorenzetti \& Carrion, 2012) e passa a ser adotado por diversos organismos multilaterais, a partir dos anos 1980, nos mais variados contextos (Jacobi \& Sinisgalli, 2012). A governança abarca, portanto, uma infinidade de temáticas perpassando pela grande parte dos conteúdos estudados nas ciências políticas e na economia política, resumindo-se nas maneiras como determinados grupos de indivíduos governam a si próprios e os meios que vivem (Câmara, 2013). Usualmente, o conceito se relaciona com a interdependência de múltiplos atores que atuam por meio de objetivos comuns, relacionando o público, o privado e a sociedade civil associada, resultando em uma série de ações (Kooiman, 1993).

O conceito de "governança ambiental" trata de arranjos interessados em construir o "bem comum" (Moura, 2016) e se relaciona com as ações entre variados atores, humanos e não-humanos, que produzem contexturas políticas, sociais e econômicas. Destacamos que circunda o conceito uma espécie de 
senso conciliatório possível de resultar das relações entre os múltiplos interesses (Zhouri, 2008). As críticas a esse uso expandido do conceito se dão pelas apropriações descontextualizadas, acríticas e até mesmo ingênuas, causando frustrações entre os atores envolvidos (Fonseca \& Bursztyn, 2009). Por esse ângulo, é fundamental que haja esforços a fim de constituir arcabouços teóricos e analíticos próprios, advindos, por exemplo, das experiências latino-americanas, unindo assim variadas correntes de pesquisa a fim de que deem conta das relaçóes multiescalares que reúnem os Estados, a sociedade civil e os atores do mercado (Castro, Hogenboom, \& Baud, 2011).

A governança ambiental também pode ser visualizada como forma de contribuir para processos de transformaçóes sociais, políticas, econômicas e ambientais que fundamentam projetos atuantes no desenvolvimento local (Espada \& Sobrinho, 2015). Nesse contexto, chamamos a atenção para os "Instrumentos Baseados no Mercado" (Pirard, 2012), que se constituem em uma forma pela qual determinadas organizações têm aplicado essa noção. Assinalamos a existência de diversas críticas a tais dispositivos (Pirard \& Lapeyre, 2014), bem como a legitimidade das decisões tomadas nesses espaços que congregam variadas organizações e diferentes atores, pois apresentam distintas escalas e níveis de poderes econômico e político (Vitale, Spécie, \& Mendes, 2009).

A governança ambiental performa fenômenos tanto no campo teórico como no prático, o que se torna uma temática interessante aos Estudos Organizacionais. Já que é estabelecida a partir da inter-relação entre as perspectivas do local e do global, não se trata de opor acontecimentos particulares aos mecanismos globais, mas compreender como se desenvolvem as aderências das experiências nos meios sociais (Chateauraynaud \& Debaz, 2017). Dar voz àqueles que participam dos eventos é uma possibilidade de obter perspectivas diferentes, como observam Ribeiro, Boava, Macedo e Pereira (2019) ao tratarem dos agentes públicos de amparo e socorro no rompimento da barragem da Samarco. Dito isso, pretendemos deixar os grandes conceitos sem forma para nos aproximarmos das múltiplas maneiras pelas quais as pessoas e os grupos experienciam os fenômenos que os afetam (Chateauraynaud, 2016). O que nos leva à pergunta de pesquisa do presente trabalho: como são desenvolvidas as experiências dos sujeitos em arranjos organizacionais caracterizados pela noção de governança ambiental?

Para responder tal questão, iniciaremos uma discussão epistemológica dividida em três subseções, uma relacionada com o histórico da noção de governança ambiental, outra na qual apresentaremos pressupostos pragmatistas e uma última com os operadores analíticos a serem implementados. Nosso ponto central com essas exposições é demonstrar, primeiramente, que tanto os posicionamentos de cunho funcionalista como crítico estabelecem a governança ambiental a partir de uma perspectiva dada pelo racionalismo cartesiano, separando natureza e experiência. Dado este panorama, visitaremos elementos epistemológicos pragmatistas que nos permitirão apresentar operadores analíticos problematizadores dessa cisão. Em seguida, traremos os elementos metodológicos e os dados de duas pesquisas etnográficas realizadas em Florianópolis, no estado de Santa Catarina: uma delas em uma Unidade de Conservação (UC) gerida pelo Instituto Chico Mendes da Biodiversidade (ICMBio) e a outra no processo de construção e desenvolvimento de uma horta comunitária gerida por diversos atores em um bairro da capital. Por fim, realizamos as análises dos dados e apresentação das considerações finais.

\section{DISCUSSÃO TEÓRICO-EPISTEMOLÓGICA}

\section{A polissemia da governança ambiental enquanto constructo e prática}

O meio ambiente passou a ser tratado como uma questão transversal e política entre países a partir dos encontros internacionais mediados pela Organização das Nações Unidas (ONU) no pós-II Guerra Mundial. As Conferências, de forma geral, resultaram em acordos internacionais que documentavam os compromissos 
firmados entre países para realizar ações preocupadas em conservar a natureza ou diminuir o ritmo de sua destruição. Estocolmo (1972) e Rio de Janeiro (1992, 2002 e 2012) receberam os encontros mais importantes até o momento. Neles, as comitivas dos países trataram da questão ambiental em formato de assembleia, como costumeiro na ONU. Resultaram em um conjunto de conceitos e aparatos consultivos e normativos que tratam desde os padrões de produção para indústrias específicas até objetivos mundiais transversais aos países para aproximá-los de um outro modelo de desenvolvimento, "mais sustentável" (Objetivos de Desenvolvimento Sustentável [ODS]).

Em meio a esses eventos, especialmente a partir dos anos 1980 (Jacobi \& Sinisgalli, 2012), a noção de governança, advinda de desenvolvimentos no campo da Teoria da Firma, mais especificamente, nos trabalhos de Ronald Coase e na redescoberta deles por Oliver Williamson (Lorenzetti \& Carrion, 2012), passou a ser largamente utilizada. Ao ser transposta para o campo ambiental, passou a ser tipificada como "governança ambiental". Como já esclarecemos na seção introdutória deste artigo, a governança é um conceito polifônico que abarca uma diversidade de atores e uma multiplicidade de perspectivas que transita do local ao global. Nesse sentido, as fronteiras entre as esferas do público e do privado são fluidas, envolvendo a articulação e relacionamento de diferentes atores, assim como negociações para definir impactos ambientais e as vias sustentáveis para mitigá-los (Garcia \& Gomes, 2016).

O conceito faz referência aos processos preocupados em conciliar os múltiplos interesses presentes em situações que envolvem o uso dos recursos ou dos bens comuns (Lorenzetti \& Carrion, 2012; Zhouri, 2008). Possibilita, portanto, tipificar uma grande diversidade de fenômenos que compreendem relações interinstitucionais que transitam entre contextos pouco delimitados do público, privado e sociedade civil (Garcia \& Gomes, 2016). Tal fato resulta em apropriações para nomear processos que implementam projetos com objetivos muito distintos, produzindo assim um fenômeno de despolitização conceitual. Além disso, o conceito tem-se fundamentado em uma espécie de "solucionismo" técnico estabelecido no liberalismo econômico (Zhouri, 2008), muito relacionado aos Instrumentos Baseados no Mercado, a serem tratados adiante, resultando em apropriações descontextualizadas, acríticas e até mesmo ingênuas, que causam frustrações entre os atores envolvidos (Espada \& Sobrinho, 2015; Fonseca \& Bursztyn, 2009).

Há algumas organizações, em especial as não governamentais (ONGs), que se especializaram em trabalhar com os processos de governança ambiental (Diáz, 2009), muito embora a legitimidade das participações dos diferentes atores nesses processos seja problematizada (Vitale et al., 2009). Uma das perspectivas ferramentais que chama a atenção por ter-se tornado comum é a de cunho neoliberal, principalmente por meio dos "Instrumentos Baseados no Mercado" (Pirard, 2012). Notamos que elas também são alvos de críticas, seja pela forma como tratam epistemologicamente a natureza (Pirard \& Lapeyre, 2014), por construírem e apoiarem narrativas de que o mercado é eficiente por si só, enquanto as pesquisas remarcam a necessidade do papel-chave e forte do Estado (Vatn, 2018), além da impossibilidade de tratar da perda da biodiversidade (Gómez-Baggethun \& Muradian, 2015).

\section{Governança ambiental: do funcionalismo à crítica, a mesma cisão}

A seção anterior deixa claro que, por conta das ações dos organismos multilaterais internacionais, a governança ambiental tornou-se um conceito amplamente utilizado, resultando em polissemia (Lorenzetti \& Carrion, 2012). Tal fato resultou em apropriações das mais diversas (Espada \& Sobrinho, 2015), influenciando certa despolitização do termo, tornando-o reflexo de um "solucionismo" fundado no liberalismo econômico (Zhouri, 2008). Os Instrumentos Baseados no Mercado são ferramentas advindas desse movimento (Pirard, 2012; Pirard \& Lapeyre, 2014) e apresentam profusas críticas quanto aos seus limites registradas na literatura (Gómez-Baggethun \& Muradian, 2015; Vatn, 2018).

À vista disso, para dar conta da complexidade enfrentada tanto pelo constructo como pela prática da governança ambiental, autores argumentam sobre a necessidade de um arcabouço próprio que advenha 
das experiências situadas (Castro et al., 2011). No entanto, argumentamos que a governança, por ser uma noção advinda do mundo empresarial (Lorenzetti \& Carrion, 2012), mesmo na sua vertente ambiental, parte epistemologicamente da cisão operada pelo racionalismo cartesiano, ou seja, “. . . é proclamada a independência da Subjetividade, cujo primeiro ato de conhecimento é a Reflexão, a consciência de si mesmo reflexiva: a consciência toma consciência de si mesma como Sujeito e como Objeto de conhecimento" (Japiassú, 2012, p. 112). Dito isso, os pressupostos que sustentam tanto o ferramental organizacional quanto a discussão crítica da noção são fundamentados no dualismo entre natureza e cultura. A partir disso, perguntamo-nos: como seria possível tratar das experiências dos sujeitos sem separá-las da natureza?

Essa questão será aprofundada na seção posterior, que trará pressupostos epistemológicos pragmatistas que fundamentam as perspectivas teóricas ligadas à "segunda onda da sociologia pragmática francesa" (Mello, 2019). Apoiar-nos-emos nelas para apresentarmos os operadores analíticos, que permitirão operar um movimento de aproximação das experiências dos sujeitos, caro aos Estudos Organizacionais (Ribeiro, Boava, Macedo, \& Pereira, 2019). Essas considerações nos permitem cuidados a fim de que não caiamos numa excessiva objetividade ligada ao materialismo ou numa profunda subjetividade baseada no cognitivismo. Argumentamos, assim, que uma possível saída possa ser realizada a partir dos Estudos Organizacionais e da análise das experiências dos sujeitos.

\section{A irredutibilidade da experiência e outras perspectivas pragmatistas para os Estudos Organizacionais}

Embora com algum tempo de publicação e diversas críticas sobre suas limitações (Paes de Paula, 2015; 2016), o estudo de Burrel e Morgan (1979) ainda é bastante referenciado para se analisar epistemologicamente o campo da Administração, em especial, dos Estudos Organizacionais. Nele, os autores realizaram um mapeamento dos posicionamentos epistemológicos presentes nesse campo científico e criaram quatro quadrantes (humanismo radical, estruturalismo radical, interpretativo e funcionalista) que se estruturam a partir dos eixos: sociologia da mudança radical/sociologia da regulação e subjetividade/objetividade (Burrel \& Morgan, 1979). Em resumo, os quadrantes intentam demonstrar como os posicionamentos epistemológicos se dão nesse campo científico.

Embora muito empregada, a proposição analítica de Burrel e Morgan (1979) não apresenta uma forma de tratar a relação entre natureza e cultura e recai sobre a dualidade objetividade e subjetividade. Mais recentemente alguns autores têm buscado ultrapassar a dicotomia entre o social e o material, por meio, por exemplo, de pesquisas voltadas à sociomaterialidade (Pimentel \& Nogueira, 2018; Russo \& Guerreiro, 2017). O campo é vasto e nos Estudos Organizacionais reverberam de maneira mais intensa a sociologia do espaço nas organizações, os estudos das ciências e tecnologias, a teoria ator-rede (sociologia da tradução) e as perspectivas sociomateriais (François-Xavier de Vaujany \& Mitev, 2013).

Embora a materialidade tenha ganhado espaço nas análises organizacionais, percebemos que a natureza ainda continua como um elemento pouco tratado. De maneira geral, as concepções filosóficas dos conceitos e dos posicionamentos epistemológicos têm-se constituído a partir de partículas gramaticais específicas, o que causa a necessidade junção e rejunção, isto é, de reagregar (Latour, 2012). Tal composição designa tipos específicos de relações conjuntivas, que constroem universos particulares, cada um com o seu próprio grau de unidade. Contudo, o universo da experiência humana é composto pelo resultado de todos esses diferentes graus (James, 1904). Há uma relação intrínseca e inerente entre experiência e natureza e não há sentido para o dualismo (Dewey, 1958). Tratar as experiências como um primado investigativo garante uma atitude epistêmica aberta à incerteza do mundo, marcada por sua não linearidade e por múltiplas escalas (Chateauraynaud \& Debaz, 2017). A experiência como a atividade perceptual do mundo social 
(James, 1904). O posicionamento apresentado até então considera o estatuto dos aspectos ambientais como elemento constitutivo das experiências, passaremos aos operadores analíticos que nos possibilitarão investigar as experiências dos sujeitos em organizações que se relacionam com processos de governança ambiental.

\section{Operadores analíticos}

Há variadas formas dos sujeitos experienciarem o mundo, elas ocorrem por meio da relação dinâmica entre as representações e o mundo sensível, caracterizada por idas e vindas e geradora de preensões, que garantem certa aderência entre o organismo e o ambiente (Chateauraynaud, 2016). Essa preensão ocorre em continuum, entre nenhuma preensão até o polo em que ela é excessiva, ou seja, não se permite o movimento. Um exemplo pode ser encontrado em uma escalada, isto é, para que ela seja colocada em prática é fundamental que o escalador tenha uma boa pegada com o ambiente (as dobras da montanha) (Bessy \& Chateauraynaud, 2014). Este conceito permite que num único movimento seja operada a relação "ação-percepção" sem necessitar de retorno a algum tipo de dualismo (Chateauraynaud \& Debaz, 2017).

Assim sendo, a experiência pode ser compreendida como as preensões entre os polos sensorial e cognitivo que ocorrem nos fluxos dos momentos de prova e das novas situações. As relaçóes entre as representações e os mundos sensíveis ocorrem em meio a fricções, justaposições e contraposições (Chateauraynaud \& Debaz, 2017), isto é, uma preensão não se dá por tempo indefinido, ela pode, em algum momento, ser colocada à prova. A partir dessas perspectivas, pressupomos que as pessoas sempre se envolvem com suspeitas e questionamentos, colocando o mundo em testes (Boltanski \& Thévenot, 2006). Para se acalmarem quanto a essas incertezas, os indivíduos exercem investigações (Dewey, 1938), o que faz com que ao invés de o aspecto social ser o fator explicativo do mundo, ele passa a ser "aquilo que deve ser explicitado e explicado por meio do modo como os atores, em meio aos momentos críticos e situações indeterminadas, fazem, desfazem e refazem suas associações heterogêneas" (Corrêa, 2014, p. 35).

As investigações realizadas para elucidar os distúrbios, advindos de provas afetivas, corporais ou qualitativas (Cefaï, 2017; Chateauraynaud, 2016), figuram como uma possibilidade de mudança de estado, isto é, as forças e entidades são alvos de qualificações, determinando, assim, durante a ação, suas relações (Chateauraynaud \& Debaz, 2017). A incerteza do social encontra alguma estabilidade, ainda que temporária, na materialidade. Nesse sentido, analiticamente, os objetos podem tornar-se um elemento importante, principalmente porque eles não são tratados de forma puramente passiva, mas como capazes de criar restrições, obrigações e também oferecer recursos (Bessy \& Chateauraynaud, 2014). O objeto torna-se a representação material de um conjunto de relações entre elementos heterogêneos (Akrich, 2016), o que torna inconcebível pensar a atividade humana de forma autônoma como se ela existisse em um universo indiferente (Pickering, 2013). No que tange às análises organizacionais, os objetos têm sido considerados à medida em que são parte das práticas espaciais cotidianas, produtoras de dinâmicas materiais e sociais específicas (François-Xavier de Vaujany \& Mitev, 2013).

\section{ASPECTOS METODOLÓGICOS}

Os dados empíricos utilizados neste artigo são fruto dos materiais de duas pesquisas de cunho etnográfico realizadas na cidade de Florianópolis, Santa Catarina. Um dos pontos transversais do presente artigo é que as pesquisas apresentam características metodológicas próximas. Elas são de natureza qualitativa (Creswell \& Poth, 2018) e contaram com a estratégia de observação participante (Spradley, 1980). Na pesquisa sobre a Unidade de Conservação (UC) foram realizadas entrevistas etnográficas (Spradley, 1979), pois tivemos a oportunidade de observar a ação dos atores - que eram funcionários públicos estáveis - durante um longo período de tempo, e na pesquisa sobre a horta comunitária, além da utilização de técnicas de entrevista 
etnográfica, foram realizadas entrevistas com base na história oral temática (Alberti, 2005; Freitas, 2006). Por conta da característica dinâmica da ação coletiva e da diversidade de atores que fizeram parte em diferentes momentos da sua história, vimos a necessidade de compreender o processo histórico que havia levado a organização a operar de determinadas maneiras. Para tanto, adotamos a história oral como estratégia de pesquisa, em conjunto com a estratégia etnográfica.

Salientamos que as etnografias têm sido formas aplicadas ao desenvolvimento de investigações nos Estudos Organizacionais (Andion \& Serva, 2006). Além do mais, há uma relação com nossas experiências como pesquisadores (Magnani, 2009). Por fim, destacamos que os processos de pesquisa ocorridos nas duas pesquisas foram alvos de discussão, sobretudo a respeito do acesso ao campo, enquanto processo político requerente de sensibilidade para tomarmos decisões e realizarmos escolhas (Cunliffe \& Alcadipani, 2016).

A UC, pesquisada entre os anos de 2014 e 2017, está inserida em um bioma marinho costeiro com uma área de 760 hectares em duas glebas. As UCs são uma categoria jurídica para áreas protegidas. Segundo o Sistema Nacional de Unidades de Conservação (SNUC, 2000), é possível dividi-las em dois grupos: proteção integral (composto por cinco subtipos), com objetivo de preservar a natureza e utilizar os recursos naturais de forma indireta, e uso sustentável (composto por sete subtipos), que tem como finalidade conservar a natureza de forma aliada ao uso sustentável dos recursos naturais. Nesta pesquisa, analisamos uma Estação Ecológica, portanto, uma UC de proteção integral. A organização conta com um espaço administrativo que é dividido com outras UCs que não detêm escritórios físicos, bem como com outras instâncias do ICMBio. Tal cenário propiciou a realização de observações e de contato nas quais estavam presentes não somente os membros da UC estudada. As entrevistas (Spradley, 1979) foram realizadas com sete sujeitos entre servidores e público interessado.

A pesquisa na horta ocorreu entre julho de 2017 e janeiro de 2019 e contou com treze sujeitos entrevistados. As atividades da organização foram objeto de análise e experiência durante o período do estudo, acompanhadas de análise documental de reportagens midiáticas e trabalhos acadêmicos no intuito de fazer um processo de triangulação de dados. Tal triangulação deu-se como segue: a análise dos documentos citados serviu de base para traçar uma linha histórica de acontecimentos significativos para a criação e desenvolvimento da horta comunitária. Essa linha histórica foi o roteiro que guiou as entrevistas realizadas com os sujeitos e ia-se complementando com novas informações que surgiam ao longo do desenvolvimento das entrevistas e da observação participante. Além dos participantes diretamente vinculados ao coletivo, houve contato com organizações locais que historicamente se envolveram na criação da horta, mapeando possíveis entrevistados.

Apresentados os contextos e os aspectos metodológicos das pesquisas realizadas, passaremos para a apresentação de dados, que será organizada entre cada um dos casos e depois analisados de maneira conjunta.

\section{APRESENTAÇÃO DOS DADOS}

\section{Horta Comunitária}

A Horta Comunitária do PACUCA está localizada no bairro do Campeche, maior área de planície da ilha de Florianópolis e um dos principais alvos da expansão imobiliária na cidade. A horta ocupa um espaço de cerca de 0,8 hectare de um terreno da União de 20 hectares localizado na parte central do bairro, onde operava desde a década de 1920 o Campo de Aviação do Campeche. A partir dos anos 1950, a área deixou de ser utilizada como campo de aviação e passou a ser administrada pela Base Aérea de Florianópolis, com a finalidade de realização de manobras militares. O bairro, que nesta época era uma área rural da cidade, passa a se urbanizar cada vez mais e, a partir da década de 1980, configura-se um conflito constante pelo destino do terreno, que é caracterizado pela participação da população local, por meio de suas associações, na busca 
de garanti-lo como um espaço público de lazer, de preservação da memória da aviação e da cultura local. Nesse sentido, propõe-se a criação do Parque Cultural do Campeche (PACUCA). Em 2014, parte do terreno foi tombado como patrimônio histórico, artístico, paisagístico e cultural, o que viabilizou juridicamente a criação da Horta Comunitária do PACUCA que, dentre, outras finalidades, busca o reestabelecimento de um corredor ecológico entre a área do PACUCA e o Morro do Lampião, importante remanescente de mata atlântica da região que também foi tombado como patrimônio histórico, artístico, paisagístico e cultural, por conta do seu valor ambiental e de sua relação com a história da aviação no local, pois no topo desse morro eram acendidos lampiões para que os aviadores pudessem visualizar a pista de pouso durante a noite.

O início da horta comunitária, articulado pela parceria entre membros de organizações da sociedade civil, públicas e empresas locais, foi composto pela presença de uma grande quantidade de pessoas engajadas de forma voluntária, o que foi diminuindo com o passar do tempo. Nos dois primeiros anos da ação coletiva houve uma grande produção de alimentos e forte participação voluntária. $\mathrm{O}$ espaço, antes conhecido como uma área abandonada, passou a ter um fluxo constante de visitantes em busca de conhecer o projeto e levar alimentos para casa. Com a manutenção do ritmo de produção de alimentos e a atenuação da participação dos voluntários, a forma como os alimentos deveriam ser divididos tornou-se um problema para a organização. Segundo um dos entrevistados, a falta de regras criou um ambiente livre, que em um primeiro momento funcionou bem, mas com o tempo passou a incomodar os voluntários, pois havia um fluxo constante de pessoas visitando o espaço com o intuito de levar alimentos.

Algumas atitudes passaram a ser tipificadas como desrespeitosas, a entrevistada 12 argumenta que se sentia incomodada pelas "pessoas que entram e colhem sem cumprimentar ninguém". As anotações do caderno de campo demonstram que as narrativas de alguns participantes passaram a tipificar certas situações de colheita sem supervisão de algum membro do grupo de voluntários como "roubos", já que a falta de coordenação para colher alimentos fez com que alguns canteiros fossem destruídos. Num dos casos relatados, houve uma tentativa de "roubo" de um canteiro inteiro durante a noite, porém, como os vegetais ainda não estavam maduros, foram abandonados todos no chão após a colheita: "No outro dia a gente chegou e estava tudo no chão, porque não estava na época de colher" (Entrevistada 12).

Esse cenário tencionou o ambiente e posicionou duas visões acerca de como desenvolver a ação coletiva. De um lado, um grupo de voluntários estabeleceu a produção (quantitativa) de alimentos como uma das finalidades mais importantes da horta comunitária, enquanto outro grupo destacava a consideração de ações educativas com vistas à aproximação com a comunidade do entorno.

"E ai\# virou uma coisa meio que vamos produzir ... Sendo que a ideia era meio que atender a comunidade, e a própria comunidade não estava sendo atendida, porque eles botavam pra correr o povo que ia ali. Então, não tinha uma coisa meio que de educação das pessoas, conscientização de que que era aquele espaço, de ensinar como colher, de fazer as pessoas darem valor pra aquilo, sabe?" (Entrevistada 11).

Identificamos assim dois grupos que debatiam sobre a condução da ação coletiva. A fala anterior, da entrevistada 11, representa o exercício crítico realizado pelo grupo composto, em sua maioria, por pessoas mais jovens advindas de fora de Florianópolis e guiadas por pressupostos da agroecologia e permacultura. O outro grupo é composto por pessoas mais velhas, em geral, aposentados nativos do bairro. As entrevistas demonstram que essas pessoas passaram suas juventudes no bairro, que na época era rural, o que as aproximou das práticas da agricultura tradicional. Denominaremos o primeiro grupo de "migrantes" e o segundo de "nativos", sendo esta última uma categoria levantada por atores do próprio campo. A separação entre os "nativos" e os "de fora" - em algumas situações denominados pejorativamente de "haoles" - apareceu com bastante frequência nas falas e nas situações relatadas pelos participantes da organização.

As anotações no caderno de campo indicam que o conflito produziu algumas ações no sentido de criar formas de se comunicar com os visitantes e de se organizar. Para se comunicar, os voluntários estabeleceram placas e camisetas, as primeiras indicavam locais ou ações específicas a serem realizadas pelos visitantes, enquanto as camisetas apontavam quem eram os voluntários presentes no espaço. Os sujeitos passaram a 
organizar-se por meio de planilhas digitais que estabeleciam escalas de trabalho. No entanto, "Não funcionou. Funcionava um pouco, mas ai\# mudava porque alguns, de dentro mesmo, não seguiam" (Entrevistada 11). $\mathrm{O}$ que fez com que se criasse um grupo em um aplicativo de mensagens instantâneas, quadros de aviso e murais de bilhetes. "Então, ai\# as coisas eram no grupo [de WhatsApp]. E eu tentei fazer um mural lá ... Ai\# o quadrinho sumiu dois dias depois" (Entrevistada 11), ou seja, também não surtiu efeito.

Diante do ambiente no qual “... era comum as pessoas, à noite, roubarem alimentos e plantas" (anotações do caderno de campo datadas de 06/03/2018), decidiu-se pela instalação de um portão para cercar e fechar o espaço, a fim de delimitar quem entra ou quem sai, contribuindo para a vigilância e diminuição das ações de desrespeito. O portão mais uma vez dividiu os voluntários nos grupos supracitados, os nativos a favor e os migrantes contra. À época da instalação do portão, havia uma menor participação dos últimos, o que aumentou o descontentamento e afastou ainda mais esses voluntários. Os nativos engrossaram a argumentação em favor da organização e normatização do espaço. A visão é de que "... Precisa ter um controle, saber o que esta\# acontecendo, quem realmente esta\# vindo, quem e\# voluntário" (Entrevistada 12).

Com a presença do portão e o aumento da produção de alimentos, os nativos decidiram sobre a política de distribuição de alimentos. As anotações destacam que parte da produção era doada para instituições de assistência social e comunidades de baixa renda, enquanto o restante era distribuído em uma feira realizada pelos próprios voluntários, no formato de contribuiçóes espontâneas em troca dos alimentos. A renda e o acesso aos alimentos foram aspectos considerados para a decisão de tal política, ao invés "de dar pra um rico, melhor dizendo, dar pra um rico que poderia comprar uma alface orgânica no supermercado de 3,80 [reais], melhor dar pra um pobre" (Entrevistado 2).

A presença dos produtos da horta na feira deu uma visibilidade distinta à ação coletiva. $\mathrm{O}$ acesso aos alimentos pela feira fez com que as visitas ao espaço físico se tornassem menos rotineiras e frutos de um processo de regulação, agenciado por regras e pela presença do portão. Ações pedagógicas, que na visão apresentada anteriormente pelo grupo de migrantes vinham no sentido de integrar a população local ao espaço da horta, por meio de oficinas, mutirões de trabalho, acolhimento e explicações sobre as regras durante as visitas cotidianas, passaram a desenvolver-se por meio de uma agenda estimulada pelas instituições de ensino locais que buscam formas de promover educação ambiental no território, agora respeitando horários marcados com a coordenação da horta comunitária. Dito isso, a próxima seção será de apresentação dos dados da Unidade de Conservação.

\section{Unidade de Conservação}

No Brasil, as áreas protegidas para conservação da natureza são chamadas de "Unidades de Conservação" (UCs). Após um longo tempo de tramitação no poder legislativo houve a aprovação, em 2010, do Sistema Nacional de Unidades de Conservação (SNUC), arcabouço jurídico-normativo que as dividiu em dois grandes grupos, proteção integral e uso sustentável. O primeiro grupo é caracterizado pelo uso indireto dos recursos naturais e o segundo, pelo uso direto e sustentável dos mesmos. A proteção integral estabelece maiores restrições às ações humanas e o uso sustentável tende à conciliação entre conservação da natureza e o uso dos recursos naturais. Neste estudo, o material etnográfico advém de uma Estação Ecológica (proteção integral), a qual tem seus objetivos declarados no decreto de criação, a saber: preservar a natureza e a realizar pesquisas científicas.

Diante desse contexto organizacional extremamente formalizado e normatizado, diferente do caso anterior, a UC atua como responsável por implementar e fiscalizar normas que regulam as relações dos humanos com a natureza. Para demarcar sua presença no território, a UC comunica-se com as pessoas, dentre outras formas, a partir de cercas e placas que limitam suas áreas nos territórios. Nas anotações do caderno de campo, distinguimos dois tipos de placas utilizadas no caso analisado: lúdico e legalista. 
Visualmente, as placas lúdicas apresentam figuras e fotografias que demonstram as finalidades da UC e sua importância de estar presente no território, como a realização de ações de conservação da natureza e de pesquisas científicas, de educação ambiental, de animais ou características do ecossistema. As placas legalistas, diferentemente, apresentam um fundo branco e são encabeçadas pelo brasão do serviço público federal. Nelas são informadas as possíveis sanções caso determinadas regras sejam desobedecidas. Outro ponto importante é que a disposição dessas placas não acontece de forma aleatória. Naqueles locais em que a circulação de pessoas esteja dentro da normalidade, ficam as placas lúdicas. Já em locais mais ermos, com potencial para os fenômenos ilegais, as placas legalistas.

Há de se destacar o poder de polícia que o ICMBio tem na área protegida e em seu entorno. Tal fato faz com que a UC se torne uma instância de recebimento de denúncias de variadas maneiras: telefonemas, redes sociais, e-mails e nos encontros com as equipes nos bairros. Retrataremos um caso no qual os denunciantes se dirigiram até a UC. Os denunciantes iniciaram a conversa dizendo que pertenciam ao bairro e eram "favoráveis" à presença da UC. Um dos indivíduos questionou: "O que vocês entendem por mangue?”. Feito o questionamento, ele iniciou uma narrativa na qual expunha a visão daquilo que de forma histórica e prática compreendia ser o manguezal. Como o ecossistema é protegido por legislação, qualquer devastação configura crime ambiental. Então, o analista ambiental presente na situação utilizou um sistema de georreferenciamento computadorizado para explicar o que é mangue. Nele, mediado pelo computador, o analista narrava os limites do manguezal, trabalhando com um mapa no qual os polígonos representam áreas determinadas. Conforme ia explicando, o analista apresentava os conceitos que estavam envolvidos na definição técnica do manguezal no território.

As produções técnicas acerca da temática ambiental aplicada ao território levam-nos a considerar a produção de expertises realizada nas UCs. Os servidores da área protegida produzem diferentes tipos de documentos que embasam tomadas de decisões próprias e de outras organizações. A UC contava com um corpo técnico bastante especializado, que a aproximava dos atores do campo científico e acadêmico. $\mathrm{O}$ caderno de campo apresenta diversas passagens que retratam as relações dos servidores com professores e pesquisadores da região. Além do mais, há instâncias específicas nas instituições ambientais federais, estaduais ou municipais responsáveis por essas produções científicas. Assim, os servidores costumam fazer parte de equipes de diferentes organizações preocupadas com o desenvolvimento de estudos científicos aplicados ao território. O poder de polícia e a função de aplicar normas regulando as ações humanas nos territórios fazem com que o material produzido embase também decisões do meio jurídico. Além do mais, o posicionamento técnico pode ainda ser demandado por grupos sociais que levantem questionamentos acerca de determinados problemas públicos.

As três formas de produção de expertises apresentadas anteriormente foram destacadas por meio do material de campo. Identificamos que a UC produz expertises a respeito do território em que atua. Organizacionalmente, percebemos que os servidores atuam em rede e contribuem a partir de suas áreas de formação. Em complemento, as entrevistas destacam a importância das ações de educação ambiental. Elas também acontecem no formato de redes constituídas por instituições de pesquisa e de educação. Um dos entrevistados destacou que, ao realizar atividades de educação ambiental, buscava a integração com as instituições próximas, localizadas no entorno da UC. Segundo ele, as crianças, em especial, são importantes influenciadores dos comportamentos dos pais e por isso são um dos grupos focalizados nas ações de educação ambiental. Expostos os dados dos dois casos, passaremos às análises deles.

\section{Análise dos Dados}

Entendendo as experiências dos sujeitos como processos de governança ambiental, leva-nos a corroborar com a perspectiva do tratamento de múltiplos interesses em situações que envolvem recursos ou bens comuns (Lorenzetti \& Carrion, 2012). Tais casos estão estabelecidos em contextos interinstitucionais que inter- 
relacionam o público, o privado e a sociedade civil (Garcia \& Gomes, 2016). A nossa aproximação em relação às experiências dos sujeitos traz uma primeira perspectiva transversal, que é da normatividade.

Os referenciais normativos apresentaram importância para a compreensão das experiências dos sujeitos nos dois casos analisados. A horta comunitária enquanto ação coletiva pouco formalizada experimentou diversas formas de se organizar e regular a ação humana no espaço. A UC, por outro lado, encontrava um forte arcabouço jurídico-normativo para balizar as ações organizacionais. Diante desse plano normativo, os momentos de prova expuseram as diferentes perspectivas apresentadas pelos sujeitos (Cefaï, 2017; Chateauraynaud \& Debaz, 2017). Na horta comunitária, analisamos processos de negociação a fim de criar e implementar tais referenciais. $\mathrm{Na} \mathrm{UC}$, enxergamos como os sujeitos percebem acerca das formas que aplicaram essa normatividade no território.

Na horta, emergiram dois grupos, nativos e migrantes, que desenvolviam ações a fim de apontar finalidades organizacionais para estabelecer as experiências dos sujeitos. Por exemplo, com o cenário de baixa participação de um dos grupos (dos migrantes), a manutenção do ritmo de produção de alimentos aliado às situações de desrespeito possibilitou a instalação do portão e a instituição de uma política própria para distribuir os alimentos. As experiências anteriores são elementos para as tomadas de decisões no presente (Bessy \& Chateauraynaud, 2014). Diante disso, alguns sujeitos utilizaram essas experiências para relacionar o acesso aos alimentos orgânicos com o poder aquisitivo das pessoas e justificar o estabelecimento da finalidade de produção de alimentos da horta, em detrimento da finalidade de educação e integração da comunidade ao espaço como forma de proporcionar o acesso a alimentos orgânicos para pessoas que não têm condições de comprá-los no supermercado. No caso da UC, muito embora haja um extenso e pesado referencial normativo sobre as ações dos sujeitos, ele não captura completamente os fluxos das experiências. Isto é, há um espaço de ação que pode ser visto por meio da lente da discricionariedade, o qual dá abertura às maneiras como as regras são interpretadas e implementadas.

A comunicação é uma prática transversal entre as duas ações coletivas. Ela não pode ser considerada como um processo relativo somente à agência dos humanos. Os casos demonstram as leituras realizadas nos ambientes pelos indivíduos, por meio das relações entre as dobras presentes no ambiente e os seus corpos (Bessy \& Chateauraynaud, 2014; Chateauraynaud \& Debaz, 2017). Os sujeitos experienciaram na horta comunitária a destruição dos canteiros e a "invasão" do espaço. $\mathrm{Na}$ área protegida, a situação da denúncia exemplifica a inter-relação entre as preensões realizadas do denunciante, com perspectivas históricas e práticas, e as do analista ambiental, com base em sua categoria profissional. A fim de garantir maior robustez à sua explanação, o analista apoia-se na experiência prática do denunciante para descrever o que é tecnicamente entendido como mangue. Para tanto, utiliza-se da mediação computadorizada por meio de um sistema de georreferenciamento.

Os objetos presentes e criados nas ações coletivas (Pickering, 2013) também participaram das comunicações. Na horta comunitária, os voluntários arquitetaram placas, murais e camisetas. De maneira geral, todas elas serviam para assinalar quem pertencia ou não ao grupo de voluntários, influenciando a maneira pela qual as pessoas deveriam comportar-se no espaço comunitário, regulando-o. Já na UC, as placas legalistas e lúdicas comunicavam os limites da área protegida e, consequentemente, a presença do Estado por meio do ICMBio no território. Essas placas propiciam performances comunicativas distintas, comunicando a importância da presença da UC e a possibilidade de sanção a comportamentos que infrinjam as normas instituídas. Assim sendo, os objetos relatados criam restrições e obrigações, além de oferecerem recursos (Bessy \& Chateauraynaud, 2014), isto é, saliências no ambiente para as ações dos sujeitos, a partir de um conjugado de relações entre artefatos heterogêneos (Akrich, 2016).

Nos momentos de prova, os sujeitos trazem experiências anteriores como um aspecto de legitimidade, assinalando o "pertencimento ao local" como um indicador importante das relaçóes estabelecidas (Chateauraynaud \& Debaz, 2017). Na horta comunitária, os indivíduos se dividiram predominantemente em dois grupos que se diferenciavam por serem ou não nativos do bairro. $\mathrm{Na} U \mathrm{C}$, na situação de realização 
de denúncias, o indivíduo de antemão assinalou seu pertencimento ao bairro. Além de ter trazido suas experiências anteriores com aquilo que costumeiramente entendia como mangue.

A ligação entre os referenciais e as saliências no ambiente está sendo tratada aqui como preensões. A capacidade de encontrar boas mediações é um efeito da expertise, que não se reduz somente aos trabalhos dos experts e profissionais (Bessy \& Chateauraynaud, 2014). Na UC, a expertise foi produzida a partir $\mathrm{da}$ variedade de categorias profissionais dos servidores lotados na área protegida atuando em rede, esses profissionais traduziam suas experiências em documentos de cunho técnico, utilizados, principalmente, nos campos jurídico e científico. A horta comunitária apresentou uma epistemologia prática ligada às experiências dos sujeitos que construíram conhecimentos híbridos advindos da agricultura tradicional (nativos), da permacultura e da agroecologia (migrantes). Esses casos evidenciaram a perspectiva de Bessy e Chateauraynaud (2014) de que a expertise não se trata estritamente de uma produção exclusivamente intelectual, mas que compreende aspectos sensoriais dos sujeitos presentes nos ambientes. Tal fato faz com que a divisão entre experts e profanos não determine de antemão aquilo que poderá ocorrer situacionalmente, possibilitando que os sujeitos se tornem protagonistas competentes a partir do momento em que criam boas mediações.

Os casos nos demonstraram ainda a centralidade das atividades de Educação Ambiental. Neles, destacaram-se tensões entre acolher a fim de educar e mudar o estado das coisas ou vigiar e punir os comportamentos não desejados. Isso nos faz questionar o senso conciliatório dado à noção de governança ambiental (Zhouri, 2008). Os conflitos retratados neste trabalho e geradores de momentos de provas apontaram, na maioria das vezes, para tais tensões. Indicando assim ora a educação e o acolhimento como forma de negociação dos estados das coisas, ora a vigilância e a punição. Nesses momentos, identificamos reorganizações das relações de força, seja reafirmando-as por meio, por exemplo, do poder de polícia ou as reestabelecendo enquanto finalidade dada à organização, como o foco na produção de alimento na horta comunitária, e a consequente regulação da entrada de visitantes na horta.

Diante do relatado, identificamos o espaço ocupado pela tensão organizacional entre as práticas e finalidades de educação ambiental e vigilância. As UCs podem ser consideradas um tipo organizacional específico que conta com um histórico em implementar o arcabouço jurídico-regulador nos territórios, para tanto, instituiu, de antemão, tais práticas em seus objetivos organizacionais. No entanto, embora esses espaços apresentem conteúdos normativos específicos, eles estão em constante conflito, já que apresentam lógicas de ação próprias e garantem sentidos específicos para a "governança ambiental”. Na horta comunitária, os espaços garantidos a essas práticas dependem de uma negociação situacional da realidade sócio-organizacional, influenciada pelos sentidos dados pelos grupos que exercem maior influência em determinado momento, bem como de suas experiências anteriores.

\section{CONCLUSÃO}

No presente trabalho, discutimos as experiências dos sujeitos em organizações ligadas à governança ambiental. Atingimos tal objetivo ao descrever e analisar as experiências dos sujeitos em dois tipos organizacionais, uma horta comunitária e uma área protegida. Argumentamos que os constructos teóricos e práticos ligados à governança ambiental partem do racionalismo cartesiano e, portanto, da cisão entre natureza e experiência. A fim de apresentarmos outras perspectivas aos Estudos Organizacionais, mais próximas das ações dos sujeitos, expusemos pressupostos epistemológicos pragmatistas e operadores analíticos fundamentados neles. Identificamos assim que a governança ambiental enquanto processo de negociação com vistas ao bem comum (Moura, 2016) acontece de maneira própria, ligada às perspectivas situacionais. Além disso, o aspecto conciliatório (Zhouri, 2008) do conceito é colocado à prova, demonstrando que o conflito é um elemento constitutivo dos dois casos, sobretudo, ao atuarem sob as tensões entre educação ambiental e vigilância. 
À guisa de conclusão, sustentamos que o posicionamento epistemológico pragmatista permitiu-nos enxergar a governança ambiental como um processo que se relaciona com as perspectivas situacionais do território em questão. "Governar" recursos e bens comuns ora relaciona-se com procedimentos de harmonização das diferentes visões presentes em uma organização, ora com ações normatizadoras e reguladoras; processos fundamentados no conflito e dependentes das negociações, desenvolvidas situacionalmente, acerca das expectativas normativas a respeito das finalidades e objetivos organizacionais. Com isso, tal posicionamento destaca a importância de dar centralidade às ações dos sujeitos no intuito de compreender grandes conceitos que abarcam um conjunto variado e extenso de conteúdos, como é o caso da governança ambiental. As limitações do presente trabalho estão na utilização de somente dois casos, muito embora os posicionamentos epistemológicos assumidos de certa forma a justifique. Para estudos futuros, sugerimos pesquisar outras formas organizativas, além de correntes teórico-metodológicas que permitam problematizar e ultrapassar a cisão entre cultura e natureza operada frequentemente nos Estudos Organizacionais.

\section{REFERÊNCIAS}

Akrich, M. (2006). Les objets techniques et leurs utilisateurs. De la conception à l'action. In: Akrich, M., Callon, M., \& Latour, B. (Org.), Sociologie de la traduction: Textes fondateurs. Presses des Mines.

Andion, C., \& Serva, M. (2006). A etnografia e os estudos organizacionais. In: R. B. de Mello, C. K. Godoi, \& A. B. da Silva (Org.), Pesquisa qualitativa em estudos organizacionais: paradigmas, estratégias e métodos (pp. 147-179). São Paulo: Saraiva.

Bessy, C., \& Chateauraynaud, F. (2014). Experts et faussaires. Por une sociologie de la perception. (2nd ed.). Paris: Éditions Pétra.

Boltanski, L., \& Thévenot, L. (2006). On Justification. Economies of Worth. (1st ed.). New Jersey: Princeton University Press.

Burrel, G., \& Morgan, G. (1979). Sociologicalparadigms and organizational analysis. London: Heinemann Educational Books.

Câmara, J. B. D. (2013). Governança ambiental no Brasil: ecos do passado. Revista de Sociologia e Politica, 21(46), $125-146$.

Castro, F. de, Hogenboom, B., \& Baud, M. (2011). Governança ambiental na América Latina: para uma agenda de pesquisa mais integrada. Ambiente \& Sociedade, 14(2), 1-13.

Cefaï, D. (2017). Públicos, problemas públicos, arenas públicas... O que nos ensina o pragmatismo (parte 2). Novos Estudos CEBRAP, 36(02), 129-142.

Chateauraynaud, F. (2016). Pragmatique des transformations et sociologie des controverses. Les logiques d'enquête face au temps long des processus. Raisons Pratiques, 25, 349-385.

Chateauraynaud, F., \& Debaz, J. (2017). Aux bords de l'irréversible. Sociologie pragmatique des transformations. Paris: Éditions Pétra.

Creswell, J. W., \& Poth, C. N. (2018). Qualitative Inquiry and Research Design: Choosing Among Five Approaches. (4th ed.). Thousand Oaks: SAGE Publications.

Cunliffe, A. L., \& Alcadipani, R. (2016). The Politics of Access in Fieldwork. Organizational Research Methods, 19(4), pp. 535-561.

Dewey, J. (1938). Logic: The theory of inquiry. New York: Henry Holt and Company.

Dewey, J. (1958). Experience and nature. New York: Dover.

Espada, A. L. V., \& Sobrinho, M. V. (2015). Manejo comunitário e governança ambiental para o desenvolvimento local: análise de uma experiência de uso sustentável de floresta na Amazônia. Administração Pública e Gestão Social, 7(4), 169-177. 
Fonseca, I. F. da, \& Bursztyn, M. (2009). A banalização da sustentabilidade: reflexões sobre governança ambiental em escala local. Sociedade e Estado, 24(1), 17-46.

Garcia, M. L. V., \& Gomes, M. V. P. (2016). Meio ambiente e arena pública: governança ambiental e suas implicações para as políticas públicas. Cadernos Gestão Pública e Cidadania, 21(69), 101-118.

Gómez-Baggethun, E., \& Muradian, R. (2015). In markets we trust? Setting the boundaries of Market-Based Instruments in ecosystem services governance. EcologicalEconomics, 117(1), 217-224.

Jacobi, P. R., \& Sinisgalli, P. A. de A. (2012). Governança ambiental e economia verde. Ciência \& Saúde Coletiva, 17(6), 1469-1478.

James, W. (1904). The World of Pure Experience. The Journal of Philosophy, Psychology and Scientific Methods, 1(20), $533-543$.

Kooiman, J. (1993). Social-Political Governance: Introduction. In: J. Kooiman (Org.), Modern Governance. New Government-Society Interactions (1st ed., pp. 1-8). London: Sage.

Latour, B. (2012). Reagregando o social: uma introdução à teoria do Ator-Rede (1st ed.). Salvador: EDUFBA; EDUSC.

Lorenzetti, J. V., \& Carrion, R. M. (2012). Governança ambiental global: atores e cenários. Cadernos EBAPE.BR, $10(3), 721-735$.

Magnani, J. G. C. (2009). Etnografia como prática e experiência. Horizontes Antropológicos, 15(32), 129-156.

Mello, F. C. de. (2019). As transformações de Francis Chateauraynaud: percepção e reflexividade na segunda onda da sociologia pragmática francesa. Sociologia \& Antropologia, 9(1), 159-184.

Moura, A. M. M. de. (2016). Introdução. In: A. M. M. de Moura (Org.), Governança Ambiental no Brasil (1st ed., p. 352). Brasília, DF: Ipea.

Paes de Paula, A. P. (2015). Repensando os Estudos Organizacionais:por uma nova teoria do conhecimento. (1st ed.). Rio de Janeiro: FGV Editorial.

Paes de Paula, A. P. (2016). Beyond paradigms in Organization Studies: The Circle of Epistemic Matrices. CadernosEBAPE.BR, 14(1), 24-46.

Pickering, A. (2013). Living in the Material World. In: Francois-Xavier de Vaujany \& N. Mitev (Org.), Materiality and Space. Organizations, Artefacts and Practices (1st ed., pp. 25-40). London: Palgrave Macmillan.

Pimentel, R., \& Nogueira, E. E. da S. (2018). Estudos baseados na prática: possibilidades metodológicas para pesquisas em estudos organizacionais. Organizaçôes \& Sociedade, 25(86), 350-370.

Pirard, R. (2012). Market-based instruments for biodiversity and ecosystem services: A lexicon. Environmental Science and Policy, (19)20, 59-68.

Pirard, R., \& Lapeyre, R. (2014). Classifying market-based instruments for ecosystem services: A guide to the literature jungle. Ecosystem Services, 9(1), 106-114.

Ribeiro, J. V. de C., Boava, D. L. T., Macedo, F. M. F., \& Pereira, J. J. (2019). O rompimento da barragem da Samarco e a construção de significados: o caso de agentes públicos de amparo e socorro aos atingidos pela lama. Farol Revista de Estudos Organizacionais e Sociedade, 6(15), 115-162.

Russo, P. T., \& Guerreiro, R. (2017). Percepção sobre a sociomaterialidade das práticas de contabilidade gerencial. Revista de Administração de Empresas, 57(6), 567-584.

Spradley, J. P. (1979). The Ethnographic Interview (1st ed.). Orlando: Harcourt Brance Jovanovich.

Spradley, J. P. (1980). Participant Observation (1st ed.). Orlando: Harcourt Brance Jovanovich.

Vatn, A. (2018). Environmental Governance - From Public to Private? Ecological Economics, 148(January), 170-177.

Vaujany, François-Xavier de, \& Mitev, N. (2013). Space in Organizations and Sociomateriality. In: Francois-Xavier de Vaujany \& N. Mitev (Org.), Materiality and Space (pp. 1-21). London: Palgrave Macmillan UK.

Vitale, D., Spécie, P., \& Mendes, J. S. R. (2009). Democracia global: a sociedade civil do Brasil, Índia e África do sul na formulação da política externa ambiental de seus países. Revista de Gestão Social e Ambiental - RGSA, 3(2), $160-178$. 
Gustavo Matarazzo, et al. Vigiar ou Educar: A Governança Ambiental como Experiência

Zhouri, A. (2008). Justiça ambiental, diversidade cultural e accountability: desafios para a governança ambiental. Revista Brasileira de Ciências Sociais, 23(68), 97-107. 